\title{
Medicines Used in Emergency
}

\section{Imai Indra $^{1}$, Eka Adhiany ${ }^{2}$}

1,2Department of Anesthesiology and Intensive Therapy, Faculty of Medicine, Universitas Syiah Kuala, Banda Aceh, Indonesia

E-mail:imai_indra@yahoo.com

\begin{abstract}
:
The aims of the study is to find the emergency medicines. The result Ine Epinephrine is a sympathomimetic, adrenergic group. Epinephrine effects can be seen in: Cardiovascular secondary hypotension, reversal epinephrine), gastrointestinal, uterine, bladder, respiratory, CNS, eye and metabolic processes. Clinical use can be seen in: Cardiovascular hypotension secondary, reversal epinephrine), gastrointestinal tract, uterus, bladder, breathing, CNS, eyes and metabolic processes. Stimulate the heart in patients with cardiac arrest and stop capillary bleeding. Ephedrine is a sympathomimetic, adrenergic class of drugs. The pharmacodynamics effect of ephedrine resembles the effect of epinephrine, the difference is that ephedrine is not a catecholamine, it is effective in oral administration, the duration of action is much longer, the central effect is stronger, but a much larger dose of epinephrine is needed, the difference being that ephedrine is not a catecholamine, it is effective in oral administration, its duration is much longer, the central effect is stronger, but a much greater dose is needed than the epinephrine dose. Like epinephrine, ephedrine acts on $a, \beta 1$ and $\beta 2$ receptors. The ephedrine cardiovascular effect resembles the effect of epi but lasts about 10 times longer..
\end{abstract}

\section{Keywords:}

emergency; medicines

\section{Introduction}

Emergency situation is a condition where someone needs immediate help, because if they don't get immediate help, it can threaten their lives or cause permanent disability. Emergency situations that often occur in the community, among others, the situation of someone who has stopped breathing, cardiac arrest, unconsciousness, accidents, injuries such as broken bones, cases of stroke, seizures, poisoning, and disaster victims. Therefore, a series of first attempts can be made at emergency conditions in order to save patients from death. Management of seriously injured patients requires rapid assessment and proper management can avoid death.

Anesthesia is a branch of medical science that underlies a variety of measures which include the provision of anesthesia or analgesia to safeguard the safety of patients undergoing surgery or other measures, assistance in resuscitation and intensive therapy for critical patients; and providing inhalation therapy and chronic pain management.

One of the measures to deal with medical emergencies is with emergency medicines. The use of emergency medicines is aimed at resuscitation or life support measures. Knowledge of these drugs is crucial to deal with life-threatening emergency situations quickly and accurately. As a general practitioner knowing the use of emergency medicines is a basic thing needed in undergoing medical practice at the Community Health Center, because emergencies can occur anywhere. 


\section{Review of Literatures}

\subsection{Epinephrine (Adrenaline)}

Epinephrine is a prototype of adrenergic drugs. Epinephrine works on all adrenergic receptors (sympathetic nerves): $\alpha 1, \alpha 2, \beta 1$ and $\beta 2$ while norepinephrine works on $\alpha 1, \alpha 2, \beta 1$ receptors so that the effect is the same as epinephrine minus the effect on $\beta 2$. Drug selectivity is not absolute, in large doses the selectivity is lost. So in large doses $\beta 2$ agonists can still cause $\beta 1$ receptor stimulation in the heart.

\subsection{Ephedrine}

Ephedrine is an alkaloid found in plants called ephedra or ma-huang. Ma-huang contains many ephedrine-like alkaloids which can then be processed into ephedrine. Herbal ingredients containing ephedrine have been used in China for 2000 years, and for decades have been a component of Chinese herbal medicine for various claims, for example slimming drugs, refreshing drugs or breath relief.

Ephedrine is a non-catecholamine class of drugs, so ephedrine has a high bioavailability and relatively long hours of work.Ephedrine has the ability to activate $\beta$ receptors and its effect can reach the central nervous system, so ephedrine is a mild CNS stimulator. Pseudoephedrine, which is one of four derivatives of ephedrine, is widely available as a mixture in decongestant drugs. However the use of ephedrine as a raw material for methamphetamine has limited sales.

\subsection{Sulfas Atropine (Anti-Muskarinik)}

Muscarinic receptors or anti-muscarinic receptors are grouped in 3 groups: 5

1. Antimuscarinic alkaloids: Atropine and Scopolamine

2. Semisynthetic derivatives

3. Synthetic derivatives

Synthesis is carried out with the intention of obtaining drugs with specific effects on certain disorders and milder side effects. This group of drugs works on muscarinic receptors with different affinity for various subtype of muscarinic receptors. Therefore there are currently antimuscarinic used for:

1. Getting peripheral effects without central effects for example, antispasmodics.

2. Local use of the eye as midriatikum.

3. Getting a central effect, for example to treat Parkinson's disease

4. Bronchodilation

5. Obtaining the effect of inhibition on gastric secretion and gastrointestinal movements.

\subsection{Aminophylline (Xanthine Derivatives: Theophylline Ethylenediamine)}

Xanthine derivatives consisting of caffeine, theophylline and theobromine are alkaloids found in plants. Since a long time ago these plant extracts were used as drinks. Caffeine is found in coffee obtained from Coffea Arabica seeds, Tea from Thea sinensis leaves contains caffeine and theophylline. Cocoa, obtained from the seeds of Theobroma cacao contain caffeine and theobromine. All three are xanthine derivatives containing methyl groups. Xantin itself is dioxypurin which has a structure similar to gout.

\subsection{Dexamethasone (Corticosteroids)}

Corticosteroids affect the metabolism of carbohydrates, proteins and fats; and also affects the functioning of the cardiovascular system, kidneys, striated muscles, nervous system 
and other organs. The adrenal cortex functions homeostatically, meaning that it is important for organisms to be able to defend themselves in the face of environmental changes. Glucocorticoids have a widespread effect because they affect the function of most body cells. The main metabolic effect of glucocorticoid secretion or administration is caused by the direct action of these hormones on cells. But the important impact is in producing a homeostatic response to insulin and glucagon. Although many of the effects of glucocorticoids are dose related and their effects are magnified when large amounts of glucocorticoids are given for therapeutic purposes

\section{Discussion}

Emergency drugs or drugs used in the emergency department are drugs that work to overcome emergency situations that threaten lives quickly and precisely. As for the kinds of emergency drugs that will be discussed in this referendum are Epinephrine, Ephedrine, Sulfas atropine, Aminophlin, Deksamethason.

\subsection{Pharmacodynamics}

\section{a. Cardiovascular}

1. The vascular effects of epinephrine mainly on small arterioles and precapillary sphincter, but veins and large arteries can also be affected. Skin, mucous and kidney blood vessels constrict because they have dominant $\alpha$ receptors.

2. Skeletal muscle vessels are dilated by low-dose epinephrine, due to activation of $\beta 2$ receptors which have a greater affinity than $\alpha$ receptors.

3. The dominance of $\alpha$ receptors in blood vessels causes an increase in peripheral resistance resulting in an increase in blood pressure. When cadarepinephrine decreases, the effect on the less sensitive $\alpha$ receptor disappears first while the effect of epinephrine on the $\beta 2$ receptor remains at this low level, causing secondary hypotension.

4. If before epinephrine has been given an $\alpha$ receptor blocker, then epinephrine administration will only cause vasodilation and a decrease in blood pressure. This symptom is called epinephrine reversal.

\section{b. GI tract}

1. Through $\alpha$ and $\beta$ receptors, epinephrine induces relaxation of the smooth muscles of the gastrointestinal tract in general: tone and reduced intestinal and gastric motility.

2. Receptor $\alpha 1, \alpha 2, \beta 1$ and $\beta 2$ receptors occur in smooth muscle cell membranes. In the pylorus and ileosecal sphincter, epinephrine causes contraction through activation of the $\alpha 1$ receptor.

\section{c. Uterus}

1. Polos The smooth muscle of the human uterus has $\alpha 1$ and $\beta 2$ receptors. The response to epinephrine varies, depending on the phase of pregnancy and the dose given. During the last month of pregnancy and during parturition, epinephrine inhibits uterine tone and contraction through $\beta 2$ receptors.

\section{d. Bladder}

1. Ine Epinephrine causes detrusor muscle relaxation via $\beta 2$ receptors, and contraction of the trigon, sphincter and smooth muscle of the prostate through $\alpha 1$ receptors, which can cause urinary difficulties and urinary retention.

\section{e. Respiration}

1. Ine Epinephrine affects breathing mainly by relaxing the bromcus muscles through the 
$\beta 2$ receptor. The effect of this bronchodilation is very clear when there is bronchial smooth muscle contraction due to bronchial asthma, histamine, estercholine, pilocarpine, bradykinin, anaphylaxis and others.

2. In asthma epinephrine also inhibits the release of inflammatory mediators from mast cells via the $\beta 2$ receptor, and reduces bronchial secretion and mucosal congestion through the $\alpha 1$ receptor.

\section{f. Central Nervous Arrangement}

1. Ine Epinephrine at therapeutic doses does not have a strong CNS stimulation effect because this drug is relatively polar so it is difficult to enter the CNS. But in many people, epinephrine can cause anxiety, anxiety, headaches and tremors.

\section{g. Eye}

1. Myryasis is easy to occur in sympathetic stimulation but not when epinephrine is dripped on the normal eye conjunctiva.

2. Ine Epinephrine usually decreases normal intraocular pressure as well as in patients with wide-angle glaucoma. This effect may be due to reduced formation of eyeball fluid due to vasoconstriction and due to increased outflow.

\section{h. Metabolic Process}

1. Ine Epinephrine stimulates glycogenolysis in liver cells and skeletal muscle through $\beta 2$ receptors, glycogen is converted to glucose-1-phosphate and then glucose-6phosphate. The liver has the enzyme glucose-6-phosphatase but the skeletal muscle does not, so the liver releases glucose while the skeletal muscle releases lactic acid.

2. Ine Epinephrine also inhibits insulin secretion due to the predominance of $\alpha 2$ receptor activation which inhibits the activation of $\beta 2$ receptors which stimulate insulin secretion. Glucagon secretion is increased through $\beta$ receptors on pancreatic $\alpha$ cells. The glucose uptake by peripheral tissue is reduced.

\subsection{Pharmacokinetics}

\section{a. Absorption}

In oral administration, epinephrine does not reach the therapeutic dose because most of it is damaged by the COMT and MAO enzymes that are abundant in the intestinal wall and liver. On subcutaneous injection, slow absorption due to local vasoconstriction, can be accelerated by massaging the injection site. Faster absorption occurs with intramuscular injection. In local inhalation, the effect is limited mainly to the airways, but systemic effects can occur, especially when large doses are used

\section{b. Biotransformation and Excretion}

Epinephrine is stable in the blood. Epinephrine degradation mainly occurs in the liver which contains many COMT and MAO enzymes, but other tissues can also damage this substance. In normal people, only a small amount of Epinephrine is present in the urine. In pheochromocytoma patients, urine contains large amounts of intact epinephrine and NE with their metabolites.

\section{Indication}

The benefits of epinephrine in the clinic are based on its effects on blood vessels, heart and bronchial smooth muscle. The main uses for epinephrine are as follows:

a. Epinephrine is the drug of choice for anaphylactic shock, for this indication epinephrine is not replaced by other adrenergic drugs. The reason is that Epinephrine works very quickly (immediately) as a vasoconstrictor and bronchodilator, so it can save lives that are 
threatened in this condition.

b. Epinephrine is also used to extend the service life of local anesthetics (by reducing local blood flow) .5

c. Epinephrine can also be used to stimulate the heart in patients with cardiac arrest for various reasons

d. Epinephrine is used locally to stop capillary bleeding, such as bleeding in the mouth or peptic ulcer.

2. Dosage and Preparation

Composition: Ephedrine HCL

Dosage: $0.5-1 \mathrm{ml}$ subcutaneous.

Dosage: Ampoules $50 \mathrm{mg} / \mathrm{ml}$ x $1 \mathrm{ml}$ x 10

Epinephrine in the preparation is a leo isomer. Epinephrine injection is a sterile solution of $1 \mathrm{mg} / \mathrm{mL}(1: 1000)$ Epinephrine $\mathrm{HCl}$ in water for SK injection, it is used to overcome anaphylactic shock and other hypersensitivity reactions. Adult dosages range from 0.2 - $0.5 \mathrm{mg}$ (0.2 - $0.5 \mathrm{~mL}$ of 1: 1000 solution).

\section{c. Side Effects and Contraindications}

The administration of epinephrine can cause symptoms such as restlessness, throbbing headaches, tremors and palpitations. These symptoms subside quickly after rest. Patients with hyperthyroidism and hypertension are more sensitive to the effects mentioned above. 5, 7 Large doses of epinephrine or accidental IV injections can cause brain hemorrhage due to severe rise in blood pressure. Even the injection of SK $0.5 \mathrm{~mL}$ of 1: 1000 solution was reported to cause sub-arachnoid hemorrhage and hemiplegia. To overcome this, a fast acting vasodilator can be given, for example nitrate or sodium nitriprussid; $\alpha$-blockers are also useful.

Epinephrine can cause ventricular arrhythmias. Ventricular fibrillation if it occurs, usually fatal; this is especially true if epinephrine is given during anesthesia with halogenated hydrocarbons, or in patients with organic heart disease. In patients with a history of angina pectoris, epinephrine administration can facilitate the onset of an attack.

\subsection{Pharmacodynamics}

The pharmacodynamic effects of ephedrine resemble the effects of epinephrine, the difference being that ephedrine is not a catecholamine, so it is effective in oral administration, the working period is much longer, the central effect is stronger, but a much larger dose than epinephrine is needed.

Ephedrine acts on $\alpha, \beta 1$ and $\beta 2$ receptors. The peripheral effect of ephedrine through direct action and through endogenous $\mathrm{NE}$ release. Its indirect work underlies the onset of tachyphylaxis on its peripheral effects. Only l-ephedrine and racemic ephedrine are used in the clinic:

a. The cardiovascular effects of ephedrine resemble the effects of epinephrine but last about 10 times longer. Systolic pressure increases, and usually also diastolic pressure, and pulse pressure increases. This increase in blood pressure is partly due to vasoconstriction, but mainly by heart stimulation which increases the strength of the heart's contractions and cardiac output.

b. The heart rate may not change due to the vagal compensation reflex. In contrast to epinephrine, a decrease in blood pressure at low doses is not evident in ephedrine.

c. Bronch Relaxation by ephedrine is weaker but lasts longer than by epinephrine. The central effects of ephedrine resemble the effects of amphetamine but are weaker. 


\subsection{Pharmacokinetics}

Onset of action: IV hammpir directly IM a few minutes

Peak effect: IV 2-5 minutes, IM less than 10 minutes

Duration of action: IV / IM 10-60 minutes

Interaction / toxicity: Increased risk of arrhythmias with volatile anesthetic drugs, depotation, by anticyclic antidepressants increases the effects of volatile anesthetics.

\section{a. Dosage and preparation}

A $30 \mathrm{mg}$ preparation in $1 \mathrm{~mL}$ ampoules $(30 \mathrm{mg} / \mathrm{mL}$ ) for IV injection, also available in $1 \mathrm{~mL}$ ampoules containing $50 \mathrm{mg}(50 \mathrm{mg} / \mathrm{mL})$.

\section{Dose:}

- Dilute 1 ampoule $30 \mathrm{mg}$ in $9 \mathrm{~mL}$ aqua bidest to get a solution containing $3 \mathrm{mg}$ of ephedrine per $\mathrm{mL}$.

- Adults 3-6 mg by slow IV injection (1-2 ml diluted solution), repeated every minute until blood pressure stabilizes.

\section{b. Indication}

1. Hypotension induced by regional anesthesia (Spinal and Epinephindural anesthesia)

2. The first choice treatment of anaphylactic shock in pregnant women

\section{c. Contraindications and side effects}

1. Give caution to patients with coronary insufficiency, hyperthyroidism and closed-angle glaucoma.

2. Can cause: Arrhythmia, hypertension.

3. Pregnant women: There are no contraindications.

4. Nursing mothers: Prevent administration (excreted in breast milk).

5. In normal doses central effects such as anxiety, headache, anxiety and sleeplessness can occur

6. At high doses it causes tremors, tachycardia and arrhythmias.

\section{d. Chemical Structure}

Atropine (a mixture of $\alpha$ and 1-hiosiamin) is mainly found in Atropa belladonna and Datura stramonium, an organic ester of tropic acid with tropanol or skopin (organic base). Although selectively inhibiting muscarinic receptors, at very large doses of atropine shows inhibitory effects also in the autonomic ganglion and skeletal muscle with nicotinic receptors.

\subsection{Pharmacodynamics}

Atropine works through cholinergic receptors, the nicotinic receptors and muscarinic receptors and their various subtypes. The nicotinic receptor is divided into 2 namely:

a. Neuronal nicotinic receptors $(\mathrm{NN})$ are nicotinic receptors found in the autonomic ganglia, adrenal medulla and CNS.

b. Muscle nicotinic receptors $(\mathrm{NM})$ are nicotinic receptors found in nerve-muscle joints.

Muscarinic receptors have 5 subtypes namely:

1. M1 receptors in the ganglia and various glands.

2. M2 receptors in the heart.

3. M3 receptors in smooth muscle and glands.

4. M4 receptors are similar to M2.

5. M5 receptors are similar to M1 
Barriers by atropine are reversible and can be overcome by giving excessive amounts of acetylcholine or giving anticholinesterases. Atropine blocks both endogenous and exogenous acetylcholine, but the barriers are much stronger against exogenous ones.

Muscarinic receptor sensitivity to antimuscarinic varies between organs. In small doses (around $0.25 \mathrm{mg}$ ) for example, atropine only suppresses secretion of saliva, bronchial mucus and sweat and has not clearly affected the heart. At larger doses $(0.5-1.0 \mathrm{mg})$ new dilated pupils are seen, impaired accommodation. and inhibition of the vagus nerve so that tachycardia is seen. An even greater dose is needed to inhibit intestinal peristalsis and glandular secretion in the stomach.1 Inhibition of this muscarinic receptor is similar to denervation of the cholinergic post-trafficking fibers and in this situation the adrenergic effect is usually more pronounced.

\subsection{Pharmacokinetics}

Atropine is easily absorbed in all places, except in the skin. Giving atropine as eye drops, especially in children can cause absorption in large amounts through the nasal mucosa, causing systemic effects and even poisoning. From the blood circulation atropine quickly enters the tissues and half of them undergo enzymatic hydrolysis in the liver. Some are excreted through the kidneys in the original form. The half-life of atropine is about 4 hours.

\section{a. Indication}

1. Emergencies

2. Treatment of sinus bradycardia / CPR, premedication (vagolysis), reverse of neuromuscular blockade (blockade of the anticholonesterase muscarinic effect), bronchospasm.

3. Airway

- Atropine is useful for reducing the secretion of nasal mucus and airways, for example in acute rhinitis, coriza, and hay fever.

- Ophthalmology

- Atropine is usually used with a strength of $0.5-1 \%$ solution, two or three drops of this solution is enough to cause mydriasis for several days to a week.

- Central nervous system

- Atropine is an additional drug besides levodopa as a treatment for Parkinsonism.

\section{b. Side effects}

Antimuscarinic side effects are all a pharmacodynamic effect. In young people the side effects of dry mouth, micturition, meteorism often occur, but not harmful. In the elderly there can be a central effect mainly in the form of dementia syndrome. Worsening urinary retention in prostate hypertrophy patients and worsening of vision in glaucoma patients.

\section{c. Dosage and preparation}

$1 \mathrm{mg}$ of atropine sulfate in $1 \mathrm{~mL}$ ampoule $(1 \mathrm{mg} / \mathrm{mL})$ given SC, IM, IV. Also available in ampules $0.25 \mathrm{mg} / \mathrm{mL}$ and $0.5 \mathrm{mg} / \mathrm{mL}$.

1. Sinus bradycardia / CPR:

- Children IV / IM / SK 10-20 $\mu \mathrm{g} / \mathrm{kg}$ minimum dosage of $0.1 \mathrm{mg}$.

- Adult IV / IM / SK 0.5-1.0 mg repeat every 3-5 minutes as indicated, maximum dose of $40 \mu \mathrm{g} / \mathrm{KgBB}$.

2. Anesthesia Premedication:

- Children: 0.01-0.02 mg / kg SC / IV

- Adult: 0.4-1 mg SC / IV 
3. Reversion of IV neuromuscular blockade $0.015 \mathrm{mg}$ with neostigmine anticholinesterases, IV $0.05 \mathrm{mg} / \mathrm{KgBB}$ with neostigmine anticholinesteration.

\section{d. Bronchodilation by inhalation}

1. Children $>6$ years $0.5 \mathrm{mg}$ SC every $4-6$ hours

2. Adult $0.25 \mathrm{mg} / \mathrm{kg}$ in $4-6$ hours

\section{e. Contraindications and side effects}

1. Do not give it to patients with urethra-prostate disorders, heart problems and glaucoma.

2. Do not give to children with high fever.

3. May cause: urinary retention, dry mouth, constipation, dizziness, headache, pupillary dilation and tachycardia.

4. Give caution and under close supervision to patients who are taking other anticholinergic drugs (antidepressants, neuroleptics, H-1 antihistamines, antiparkinsins etc.)

5. There are no contra indications in pregnant women.

6. Prevent use in breastfeeding women.

\subsection{Pharmacodynamics}

Theophylline inhibits the phosphodiesterase (PDE) enzyme thereby preventing the breakdown of cAMP and cGMP into 5-AMP and 5-GMP, respectively. Inhibition of PDE causes the accumulation of cAMP and cGMP in cells thereby causing smooth muscle relaxation, including bronchial smooth muscle.

Theophylline is a competitive antagonist at adenosine receptors. Adenosine can cause bronchoconstriction in asthma patients and strengthen the release of mediators from mast cells induced by immunological stimuli. Therefore the inhibition of adenosine action is also a mechanism of action for theophylline to overcome bronchoconstriction in asthma patients.

\subsection{Pharmacokinetics}

Methylxanthine is quickly absorbed after oral, rectal or parenteral administration. Liquid or non-coated tablet preparations will be absorbed quickly and completely. Absorption also takes place completely for some types of slow release preparations. Theophylline absorption in the form of soluble salts, for example theophylline $\mathrm{Na}$ glycinate or theophylline choline is no better.

Parenteral or rectal theophylline preparations still cause complaints about the gastrointestinal tract, nausea and vomiting. Apparently these symptoms are related to plasma theophylline levels. Gastrointestinal complaints caused by local irritation can be avoided by giving the drug along with food, but there will be a decrease in the absorption of theophylline. On an empty stomach, a liquid form of theophylline preparation or a non-coated tablet can produce peak plasma levels within 2 hours while caffeine within 1 hour 5

Methylxanthine is distributed throughout the body, across the placenta and into breast milk. The volume of distribution of caffeine and theophylline is between 400 and $600 \mathrm{~mL} /$ $\mathrm{kg}$. Methylxanthine elimination is mainly through metabolism in the liver. Most of it is excreted with urine in the form of methyluric acid or methylxanthine. Less than $20 \%$ theophylline and 5\% caffeine will be found in urine in its full form. The half-life of theophylline plasma in adults is 8-9 hours and in young children is approximately 3.5 hours. In patients with liver cirrhosis or acute pulmonary edema, the rate of elimination varies greatly and takes place more slowly. 


\subsection{Indications}

\section{a. Bronchial Asthma}

Theophylline compound is one of the drugs needed for long-lasting asthma attacks (asmatikus status). In overcoming the asthmatic status various actions are required including oxygen use, bronchial mucus aspiration, and administration of sympathomimetic drugs, bronchodilators, expectorants and sedatives. One of the most effective bronchodilators is theophylline. Besides theophylline can be used as prophylaxis against asthma attacks

In asthma patients, theophylline therapy levels are required at least 5-8 $\mu \mathrm{g} / \mathrm{mL}$, while the toxic effects begin to be seen at levels of $15 \mu \mathrm{g} / \mathrm{mL}$ and more often at levels above $20 \mu \mathrm{g}$ / $\mathrm{mL}$. Therefore, in the treatment of asthma, theophylline levels should be maintained at around $10 \mu \mathrm{g} / \mathrm{mL}$. Because of the large variations in the speed of theophyllin elimination, the dosage needs to be determined individually based on plasma levels of monitoring. In addition, individual responses that are also quite varied cause theophylline needs to be monitored for its use in therapeutic drug monitoring.

To overcome the great bronchial spasm epinephrine and asmatic status, aminophyllin IV should be given a loading dose of $6 \mathrm{mg} / \mathrm{kg}$ body weight which is equivalent to theophylline $5 \mathrm{mg} / \mathrm{kg}$ body weight. This drug is given intravenously for 20-40 minutes. If the therapeutic effect has not been achieved and there are no signs of intoxication, then a dose of $3 \mathrm{mg} / \mathrm{kgBB}$ can be added by infusion slowly. Furthermore, the optimal effect can be maintained by infusion of $0.5 \mathrm{mg} / \mathrm{kg} /$ hour for normal adults and non-smokers. Combination with $\beta 2$-adrenergic agonists such as metaproterenol or terbutalin actually increases the effect of theophylline bronchodilation so that doses can be used with a smaller risk of side effects

\section{b. Chronic Obstructive Pulmonary Disease (COPD)}

Theophylline is also widely used in this disease with the same purpose as the treatment of asthma. However, other symptoms related to the cardiovascular system due to chronic obstructive pulmonary disease such as pulmonary hypertension, poor heart failure in the cor pulmonale, are not corrected by theophylline

\section{c. Apnea in Premature Babies}

Premature infants often occur with epinephrine-apnea lasting more than 15 seconds with bradycardia. This can lead to recurrent hypoxemia and neurological disorders, which may be associated with fairly severe systemic disease. Various studies have shown that administration of oral theophylline or IV can reduce the duration of apnea. For this reason, theophylline is sufficient to be given in doses that reach plasma levels of 3-5 $\mu \mathrm{g} / \mathrm{mL}$ which is 2.5-5 $\mathrm{mg} / \mathrm{kgBW}$ and then it is maintained at a dose of $2 \mathrm{mg} / \mathrm{kgBW} /$ day.

\section{d. Dosage and dosage}

White crystals, bitter and slightly soluble in water. In Indonesia, available in various dosage forms for oral use, namely $130 \mathrm{mg}$ theophylline soft capsules / capsules; $150 \mathrm{mg}$ theophylline tablets; late film membrane tablets containing $125 \mathrm{mg}$, theophylline, $250 \mathrm{mg}$ and $300 \mathrm{mg}$; syrup / elixir containing $50 \mathrm{mg} / 5 \mathrm{~mL}$ of theophylline, $130 \mathrm{mg} / 15 \mathrm{~mL}$ and $150 \mathrm{mg}$ / $15 \mathrm{~mL}$. Theophylline is also available in fixed combination with ephedrine for bronchial asthma. Aminophylline is a theophylline salt for IV use, available in ampules $10 \mathrm{~mL}$ containing $24 \mathrm{mg}$ of aminophylline every milliliter. 


\subsection{Pharmacodynamics}

\section{a. Metabolism}

Changes in carbohydrate, protein and fat metabolism such as the occurrence of gluconeogenesis in the liver, glycogenesis, stimulates lipogenesis and inhibits lipolysis so that there is an increase in fat deposits (Bufallo hump), reduction in muscle mass and osteoporosis in bones.

\section{b. Cardiovascular System}

Cardiovascular system disorders that arise in adrenal insufficiency or in hypercortisism are actually very complex and not all are clearly known. Corticosteroids can affect the cardiovascular system directly or indirectly. The indirect effect is on water and electrolyte balance while the direct effect of steroids on the cardiovascular system includes capillaries, arterioles and myocards.

\section{c. Skeletal Muscle}

To maintain skeletal muscle in order to function properly, adequate amounts of corticosteroids are needed. But if this hormone is excessive, arises the disruption of skeletal muscle function. In adrenal insufficiency or patients with Addison's disease, there is a decrease in the working capacity of the skeletal muscles so that complaints can arise easily tired and weak.

\section{d. Central Nervous System}

Corticosteroids can affect the central nervous system both directly and indirectly, although the latter cannot be ascertained. The indirect effect is due to its effect on carbohydrate metabolism, circulatory system and electrolyte balance. The existence of steroid effects on the central nervous system can be seen from the emergence of changes in mood, behavior, EEG and brain sensitivity in those who are using corticosteroids especially for a long time.

\section{e. Blood Forming Elements}

Glucocorticoids can increase hemoglobin levels and red blood cell count, this is evident from the frequent emergence of polycythemia in Cushing's syndrome. Glucocorticoids can also increase the number of polymorphonuclear leukocytes, because they accelerate the entry of these cells into the blood from the bone marrow and reduce the speed at which cells move from the circulation. Conversely the number of lymphocyte cells, eosinophils, monocytes and basophils in the blood can decrease after administration of glucocorticoids.

\section{f. Anti-inflammatory Effect}

Cortisol and its synthetic analogs can prevent or suppress the onset of inflammatory symptoms due to radiation, infection, chemicals, mechanics or allergens. Microscopically this drug inhibits early inflammatory phenomena namely edema, fibrin deposits, capillary dilatation, leukocyte migration to inflammatory sites and phagitic activity. it can also inhibit further manifestations of inflammation, namely capillary and fibroblast proliferation, collagen collection and brush matrix formation. Corticosteroids are often called life saving drugs and often cause a masking effect.

\subsection{Pharmacokinetics}

Cortisol and its synthetic analogs in oral administration are well absorbed. To reach high levels quickly in body fluids, cortisol esters and synthetic derivatives are given IV. To get the old effect cortisol and esters are given IM. 
Changes in chemical structure greatly affect the rate of absorption, start of work and length of work because they also affect the affinity of the receptors, and protein binding. Prednisone is a prodrug that is quickly converted into prednisolone, its active form in the body. Glucocorticoids can be absorbed through the skin, conjunctival sac and synovial space. Long-term use in large areas of the skin can cause systemic effects, between suppression of the adrenal cortex.

\section{a. Indication}

- Inflammatory syndrome in severe infections of typhoid fever, acute subglottis laryngitis etc.

- Maturation of the fetal lungs, in threatening preterm labor before 34 weeks' gestation.

- For allergic reactions (anaphylactic shock and anasarka edema) and asthmatic status, use hydrocortisone.

- Prevention of rejection of organ transplants.

- Bronchial asthma.

\section{b. Dosage}

$4 \mathrm{mg}$ dosage of dexamethasone phosphate in $1 \mathrm{~mL}$ ampoules $(4 \mathrm{mg} / \mathrm{mL})$ by IM, IV injection or infusion.

Dosage and Duration

- Inflammatory syndrome in severe infections.

The dosage and situation varies greatly depending on the severity of the infection and clinical response:

Children: 0.2-0.4 mg / kg / day

Adult: initial dose $0.5-24 \mathrm{mg} /$ day

- Maturation of fetal lungs

Given to the mother: $6 \mathrm{mg}$ by IM injection every 12 hours for 2 days (total dose: 24 $\mathrm{mg})$

\section{c. Contraindications and side effects}

- For systemic infections, it is only given if the patient is on antibiotic therapy.

- In conditions of treatment longer than 10 days, reduce the dose gradually to prevent failure of the adrenal glands.

- Pregnant women: there are no contraindications.

- Nursing mothers: no contraindications.

\section{Conclusion}

Ine Epinephrine is a sympathomimetic, adrenergic group. Epinephrine effects can be seen in: Cardiovascular secondary hypotension, reversal epinephrine), gastrointestinal, uterine, bladder, respiratory, CNS, eye and metabolic processes. Clinical use can be seen in: Cardiovascular hypotension secondary, reversal epinephrine), gastrointestinal tract, uterus, bladder, breathing, CNS, eyes and metabolic processes. Stimulate the heart in patients with cardiac arrest and stop capillary bleeding.

Ephedrine is a sympathomimetic, adrenergic class of drugs. The pharmacodynamic effect of ephedrine resembles the effect of epinephrine, the difference is that ephedrine is not a catecholamine, it is effective in oral administration, the duration of action is much longer, the central effect is stronger, but a much larger dose of epinephrine is needed, the difference being that ephedrine is not a catecholamine, it is effective in oral administration, its duration is much longer, the central effect is stronger, but a much greater dose is needed than the 
epinephrine dose. Like epinephrine, ephedrine acts on $\alpha, \beta 1$ and $\beta 2$ receptors. The ephedrine cardiovascular effect resembles the effect of epi but lasts about 10 times longer. At Sulfas atrofin is a muscarinic receptor inhibitor that is classified as an antimuscarinic alkaloid. Astropine works through cholinergic receptors, namely nicotinic receptors and muscarinic receptors and various subtypes (M1, M2, M3, M4, M5, M6) administration of excessive amounts of acetylcholine or administration of anticholinesterases.

Aminophylline is a xanthine derivative consisting of caffeine, theophylline and theobromine; is an alkaloid found in plants. Theophylline is a competitive antagonist in adenosine receptors. Theophylline also has anti-inflammatory effects and inhibits the release of mediators from inflammatory cells. Indications of this drug are bronchial asthma, COPD and apnea in newborns. Eks Dexamethasone is a group of corticosteroids, has a wide spread effect because it affects the function of most body cells.

\section{References}

Dorland. Kamus Kedokteran. Jakarta. EGC.2006

Muhiman, Muhadi,dkk. Anestesiologi. Jakarta. FKUI.2004

Soenarto Ratna F. Chandra Susilo. Buku Ajar Anestesiologi. Departemen Anestesiologi dan Intensive Care - FKUI. Jakarta.2012

Tjay, Tan Hoan \& Kirana H. Obat-Obat Penting. Jakarta: Elex Media Komputindo. 2007

Gunawan G, Sulistia. Farmakologi dan Terapi Edisi 5. Jakarta: Gaya Baru. 2007

Mark S. Link, Chair; Lauren C. Berkow; Peter J. Kudenchuk. et al. Adult Advanced Cardiovascular Life Support in : Guidelines Update for Cardiopulmonary Resuscitation and Emergency Cardiovascular Care. American Heart Association. 2015

Kabo P. Bagaimana Menggunakan Obat-obat Kardiovaskular secara Rasional. Jakarta: Balai Penerbit FKUI. 2010

PERKI. Buku Ajar Kursus Bantuan Hidup Jantung lanjut 2016. Jakarta.PERKI.2016

Katzung G, Bertram. Basic and Clinical Pharmacology 10th Ed. United states of America: McGraw-Hill Companies. 2007 